\title{
Analysis of the impact of thermal resistance of the roof on the performance of photovoltaic roof tiles
}

\author{
Dariusz Kurz ${ }^{1, *}$, and Ryszard Nawrowski ${ }^{1}$ \\ ${ }^{1}$ Poznan University of Technology, Faculty of Electrical Engineering, Institute of Electrical Engineering and Electronics, \\ St. Piotrowo 3a, 60 - 965 Poznań, Poland
}

\begin{abstract}
The paper explores the issues related to the impact of thermal resistance of the roof on the electrical parameters of photovoltaic roof tiles. The methodology of determination of the thermal resistance and thermal transmittance factor was presented in accordance with the applicable legal regulations and standards. A test station was presented for the purpose of measurement of the parameters of photovoltaic roof tiles depending on the structure of the roof substrate. Detailed analysis of selected building components as well as their impact on the design thermal resistance factor and thermal transmittance factor was carried out. Results of our own studies, which indicated a relation between the type of the roof structure and the values of the electricity generated by photovoltaic tiles, were presented. Based on the calculations, it was concluded that the generated outputs in the respective constructions differ by maximum $6 \%$. For cells with the highest temperature, the performance of the PV roof tiles on the respective roof constructions fell within the range between $0.4 \%$ and $1.2 \%$ (depending on the conducted measurement) and amounted to $8.76 \%$ (in reference to $9.97 \%$ for roof tiles with the lowest temperature).
\end{abstract}

\section{Introduction}

A photovoltaic roof tile is an example of a BIPV (Building Integrated Photovoltaics) element which integrates the roof covering with PV cells. The BIPV elements, except the generation of electric current in the process of photovoltaic conversion, must meet the requirements set for building materials. In the case of solar roof tiles installed in the roof, they must ensure appropriate water, thermal and sound insulations. Additionally, the solar roof tiles, as compared with the traditional PV panels installed on the supporting structure over the roof, as a consequence of poorer wind cooling, are subject to the faster heating of PV cells and are characterised by lower performance $[1,2]$. On top of this, the photovoltaic tiles cannot be placed on solar tracking systems which would increase the generated power outputs [3]. Thermal processes occurring within the roof space (such as heat exchange by convection and radiation) necessitate the performance of complex analytical calculations (using criterial numbers, principles of probability or numerical calculations) by means of specialist computer software or parallel calculations [4-6].

Continuously growing demand for electricity (largely, also the demand of individual recipients) entails the need to obtain it from other sources. However, photovoltaic micro-installations constitute a certain danger for the power system, which is related to the hardly predictable quantity of produced electricity, its transmission to power plants or other recipients through power lines or the electromagnetic impact on the surrounding environment $[7,8]$.

Growing requirements set for newly built buildings, which refer to their energy-efficiency, necessitate the application of building materials with the lowest thermal transmittance factor $U\left[\mathrm{~W} / \mathrm{m}^{2} \mathrm{~K}\right]$ (i.e. with a large thermal resistance $R\left[\mathrm{~m}^{2} \mathrm{~K} / \mathrm{W}\right]$ ). In the 90 -ties in Poland, the thermal transmittance factor for a building roof was established at the level of $0.45 \mathrm{~W} / \mathrm{m}^{2} \mathrm{~K}$, while at present, pursuant to the Regulation of the Minister of Infrastructure of 1 January 2017, it may not exceed $0.23 \mathrm{~W} / \mathrm{m}^{2} \mathrm{~K}[9,10]$. Hence, the roof insulation significantly affects a decrease in efficiency of electricity generation from photovoltaic roof tiles, which is of no importance in the case of performance of traditional PV panels $[1,2]$.

\section{Methodology of determination of thermal resistance and thermal transmittance factor of the roof.}

\subsection{Thermal transmittance factor $U$}

Determination of the thermal insulation of roofs must be carried out in accordance with the applicable legal acts, i.e. at present, PN-EN ISO 6946:2008. The thermal transmittance factor $U$ for a building partition, with the

Corresponding author: dariusz.kurz@put.poznan.pl 
assumption of the one-dimensional heat flow must be determined on the basis of the following equation [10]:

$$
U=\frac{1}{R_{T}} \leq U_{\max }
$$

where:

$R_{T}$ - total thermal resistance.

The value of the thermal resistance is determined in accordance with the following equation [10]:

$$
R=\frac{d}{\lambda}
$$

where:

$d$-thickness of a layer of material in a component [m],

$\lambda$ - design thermal conductivity coefficient of the material calculated in accordance with ISO 10456, or coefficient taken from values given in the table $[\mathrm{W} / \mathrm{mK}]$.

\subsection{Total thermal resistance of the building component consisting of homogenous layers}

Total thermal resistance $R_{T}$ of a flat building component which consists of homogenous layers thermally perpendicular to the heat stream must be calculated from the following formula [10]:

$$
R_{T}=R_{s i}+R_{1}+R_{2}+\cdots+R_{n}+R_{s e}
$$

where:

$R_{s i}$ - heat transfer resistance on the inner surface,

$R_{1 \ldots n}-$ design thermal resistance of each layer,

$R_{s e}-$ heat transfer resistance on the outer surface.

\subsection{Total thermal resistance of the building component consisting of homogenous and inhomogeneous layers}

The hipped roof end is an inhomogeneous partition, therefore, it is necessary to calculate supremum $R_{T}$ ' and infimum $R_{T}$ " of the total thermal resistance for the repeatable section of a partition (the so called component). Such a repeatable section for the hipped roof end is the component with the width equal to the axial spacing of a rafter. Further calculations are carried out in an identical manner as is the case with homogenous partitions. The total thermal resistance of the component which consists of homogenous and inhomogeneous layers parallel to each other can be determined from the following formula [10]:

$$
R_{T}=\frac{R_{T}{ }^{\prime}+R_{T}{ }^{\prime \prime}}{2}
$$

Prior to this, the partition must be divided into sections consisting of thermally homogenous layers and their relative areas must be determined in accordance with the formula given below [10]:

$$
f_{a \ldots n}=\frac{A_{a \ldots n}}{A}
$$

where:

$f_{a \ldots n}-$ relative areas of each section [-],
$A_{a \ldots n}$ - area of the section perpendicular to the direction of heat flow $\left[\mathrm{m}^{2}\right]$,

$A$ - total area of the partition perpendicular to the direction of heat flow $\left[\mathrm{m}^{2}\right]$, whereby

$$
f_{a}+f_{b}+\cdots+f_{n}=1
$$

Fig. 1 presents the cross-section of the roof surface with a division into sections and layers (based on the example of a roof with boards, top-cover membrane and mineral wool). Symbol $x$ marks a counter-batten, and symbol $y$ stands for a rafter. The component with the width from the half of one rafter to the half of the other rafter was assumed as the repeatable section. It is possible to distinguish three sections in it (two identical sections $a$ and one section $b$ ). On the other hand, the roof consists of 6 layers $(A-H)$. The specified layers comprise:

- $A$ - pine rafters and mineral wool,

- $H$ - only pine rafters (without wool),

- $B$ - pine boards,

- $G$ - vapour-permeable film,

- $C$-top-cover membrane,

- $D$ - pine counter-battens and air void,

- $E$ - pine battens,

- $F$-photovoltaic roof tile.

The respective sections (visible in Fig.1) include:

- $a$ - pine rafters and pine boards with top-cover membrane or vapour-permeable film (depending on the type of the roof structure), the width of the section is $g_{l}=0.04 \mathrm{~m}$,

- $\quad b$ - mineral wool, boards and top-cover membrane or vapour-permeable film or air void (depending on the type of the roof structure), the width of the section is $g_{2}=0.72 \mathrm{~m}$.

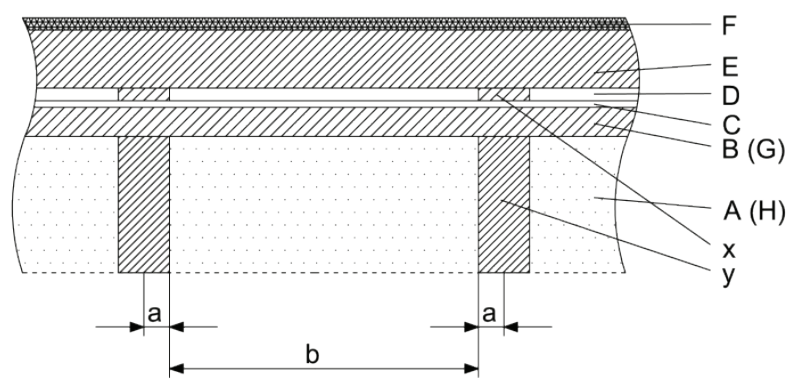

Fig. 1. Cross-section of the roof surface with a division into sections $(a, b)$ and layers $(A-H)$.

During the determination of the thermal resistance factors of the roof structure, layers $A, B, C$ as well as $G$ and $H$, which will replace layers $A$ and $B$ respectively in other types of roof structures subjected to consideration in this paper, will be of particular importance. Details regarding the layers are given below in the paper.

\subsection{Supremum of total thermal resistance $R_{T}$ '}

The supremum of total thermal resistance $R_{T}{ }^{\prime}$ is determined with the assumption of a one-dimensional thermal stream perpendicular to the surface of the component in accordance with the formula below [10]: 


$$
\frac{1}{R_{T}{ }^{\prime}}=\frac{f_{a}}{R_{T a}}+\frac{f_{b}}{R_{T b}}+\cdots+\frac{f_{n}}{R_{T n}}
$$

where:

$R_{T a}, R_{T b}, \ldots, R_{T n}$ - total thermal resistances from the environment to the environment of each section, calculated in accordance with the formula (3).

\subsection{Infimum of total thermal resistance $R_{T}$ "}

The infimum of total heat resistance $R_{T}$ " is determined with the assumption that all the surfaces parallel to the surface of the component are isothermal. Equivalent thermal resistance $R_{j}$ of each thermally inhomogeneous layer is calculated from the following equation [10]:

$$
\frac{1}{R_{j}}=\frac{f_{a}}{R_{a j}}+\frac{f_{b}}{R_{b j}}+\cdots+\frac{f_{n}}{R_{n j}}
$$

where:

$j$-consecutive component layer in the section.

The standard [8] also allows for an optional method of determination of $R_{j}$ in accordance with the following formula:

$$
R_{j}=\frac{d_{j}}{\lambda_{j}{ }^{\prime \prime}}
$$

where:

$d_{j}$ - thickness of the thermally inhomogeneous layer [m],

$\lambda j$ " - equivalent thermal conductivity coefficient of the inhomogeneous layer, whereby:

$$
\lambda_{j} "=\lambda_{a j} f_{a}+\lambda_{b j} f_{b}+\cdots+\lambda_{n j} f_{n}
$$

The infimum of the total thermal resistance is (based on relation 3 ) equal to [8]:

$$
R_{T}^{\prime \prime}=R_{s i}+R_{1}+R_{2}+\cdots+R_{n}+R_{s e}
$$

If the air layer is part of the inhomogeneous layer, it can be treated as a material with equivalent thermal conductivity coefficient for which parameters are determined by the standard [10].

\section{Types of roof structures}

There are several types of roof structures in singlefamily buildings depending on the preferences of the house owners, their financial capacities and the functions of the attic. The space under the roof can be used as a habitable attic (with the possibility of creation of accommodation spaces) or inhabitable attic (unheated premises). The function of the attic determines its temperature, therefore it will influence the process of heat exchange through the roof covering and roof insulation, thus, the performance conditions of the photovoltaic roof tiles. The working PV roof tiles will transfer the heat to the roof structure, whereby the heat will be accumulated and transferred to the attic to an extent that will depend on the thermal resistance of the structure. The most frequently encountered roof substrates include:
- D1 - vapour-permeable film insulated with mineral wool (for habitable and inhabitable attics),

- D2 - vapour-permeable film without insulation (for inhabitable attics),

- $\quad$ D3 - boards and top-cover membrane insulated with mineral wool (for habitable attics).

The paper analyses the three most frequent roof structures mentioned above in terms of estimation of their thermal resistance and impact on the performance of photovoltaic roof tiles, related to an increase in the temperature and a decrease in the efficiency of electricity generation.

In certain roof structures, some layers are absent or are replaced by others (given in brackets). The detailed specification of the materials occurring in the respective types of roof structures is listed in Table 1. (where "+" means the presence and "-" the absence). The data of the structural (construction) materials applied in the built fragments of roofs (visible in Fig. 2) was collected in Table 2 (based on the datasheet of materials or the standard [10]).

Table 1. Specification of materials in the respective types of roof structures.

\begin{tabular}{|c|c|c|c|c|c|c|c|c|}
\hline \multirow{2}{*}{ Roof } & \multicolumn{7}{|c|}{ Layer } \\
\cline { 2 - 9 } & A & H & B & G & C & D & E & F \\
\hline D1 & + & - & - & + & - & + & + & + \\
\hline D2 & - & + & - & + & - & + & + & + \\
\hline D3 & + & - & + & - & + & + & + & + \\
\hline
\end{tabular}

Table 2. Values of parameters of building materials [10].

\begin{tabular}{|c|c|c|c|c|}
\hline Material & $\begin{array}{c}\boldsymbol{d} \\
{[\mathbf{m}]}\end{array}$ & $\begin{array}{c}\boldsymbol{\lambda} \\
{[\mathbf{W} / \mathbf{m} \mathbf{K}]}\end{array}$ & $\begin{array}{c}\boldsymbol{R} \\
{\left[\mathbf{m}^{2} \mathbf{K} / \mathbf{W}\right]}\end{array}$ & $\begin{array}{c}\boldsymbol{U} \\
{\left[\mathbf{W} / \mathbf{m}^{2} \mathbf{K}\right]}\end{array}$ \\
\hline $\begin{array}{c}\text { 1. Mineral } \\
\text { wool }\end{array}$ & 0.1 & 0.042 & 2.3810 & 0.42 \\
\hline $\begin{array}{c}\text { 2. Rafter } \\
\text { (0.08 m } \\
\text { wide) }\end{array}$ & 0.1 & 0.3 & 0.3333 & 3 \\
\hline $\begin{array}{c}\text { 3. Board } \\
\text { 4. } \\
\text { Membrane }\end{array}$ & 0.025 & 0.3 & 0.0833 & 12 \\
\hline $\begin{array}{c}\text { 5. Film } \\
\text { 6. }\end{array}$ & 0.0002 & 0.04 & 0.0050 & 200 \\
\hline $\begin{array}{c}\text { 6ounter- } \\
\text { batten }\end{array}$ & 0.01 & 0.3 & 0.0333 & 30 \\
\hline $\begin{array}{c}\text { 7. Batten } \\
\text { (0.06 m } \\
\text { wide) }\end{array}$ & 0.04 & 0.3 & 0.1333 & 7.5 \\
\hline $\begin{array}{c}\text { 8. PV roof } \\
\text { tile }\end{array}$ & 0.0055 & 0.8545 & 0.0064 & 155.5 \\
\hline
\end{tabular}

The design values of physical properties for the wooden elements (rafter, board, counter-batten and batten reported in table 2) were assumed on the basis of PN-EN 
6946:1999 for the pine wood cut along the medium density $550 \mathrm{~kg} / \mathrm{m}^{3}$ in semi-humid conditions [10].

The values of heat transfer resistances from the inner side $R_{s i}=0.17 \mathrm{~m}^{2} \mathrm{~K} / \mathrm{W}$, outer side $R_{s e}=0.04 \mathrm{~m}^{2} \mathrm{~K} / \mathrm{W}$ and for the PV tile were assumed or calculated in accordance with the standard [10].

\section{Determination of roof parameters}

In accordance with the applicable regulations and methodology reported in section 2 of this paper, thermal resistances and thermal transmittance factors were determined for three different roof structures (described in detail in section 3). The detailed calculations were presented only for roof D3, and the values of the obtained parameters for each type of roof were listed in table 3 .

\subsection{Determination of supremum $R_{T}$ ' for sections $a$ and $b$}

In order to determine supremum $R_{T a}$ and $R_{T b}$ for the respective sections, it is necessary to take into account the layers occurring in them (in accordance with the numeration of materials in table 2):

$$
\begin{aligned}
& R_{T a}=R_{s i}+R_{2}+R_{3}+R_{4}+R_{s e} \\
& R_{T b}=R_{s i}+R_{1}+R_{3}+R_{4}+R_{s e}
\end{aligned}
$$

Values $R_{i}$ are determined in accordance with equation (2). The total area of partition $A$ was determined as the product of thickness of the roof structure and the width of the repeatable component section:

$$
A=\left(2 g_{1}+g_{2}\right) \cdot\left(d_{2}+d_{3}+d_{4}\right)
$$

The relative area of each section $f_{a}, f_{b}$ was determined as follows:

$$
\begin{aligned}
& f_{a}=\frac{g_{1} \cdot\left(d_{2}+d_{3}+d_{4}\right)}{A} \\
& f_{b}=\frac{g_{2} \cdot\left(d_{2}+d_{3}+d_{4}\right)}{A}
\end{aligned}
$$

The supremum was determined in accordance with equation 7:

$$
\frac{1}{R_{T}{ }^{\prime}}=\frac{f_{a}}{R_{T a}}+\frac{f_{b}}{R_{T b}}+\frac{f_{a}}{R_{T a}}
$$

\subsection{Determination of infimum $R_{T}$ " for layers $A, B$ and $C$}

In each of the layers, there is one material for which it is necessary to determine the equivalent thermal conductivity coefficient and then the equivalent thermal resistance in accordance with equations (8) - (11):

$$
\lambda_{A} "=2 \lambda_{2} f_{a}+\lambda_{1} f_{b}
$$

value of the total infimum:

$$
R_{T}^{\prime \prime}=R_{s i}+R_{A}+R_{B}+R_{C}+R_{s e}
$$

\subsection{Determination of the value of $R_{T}$ and $U$ for the roof}

Having determined the values of the infimum and supremum of a component, it is possible to calculate the value of total thermal resistance $R_{T}$ for it, consisting of homogenous and inhomogeneous layers parallel to each other, using equation (4), and the thermal transmittance factor $U$ in accordance with formula (1).

\subsection{Specification of determined parameters for

\begin{tabular}{|c|c|c|c|c|}
\hline \multicolumn{2}{|c|}{ Parameter } & \multicolumn{3}{|c|}{ Values } \\
\hline \multirow{2}{*}{ Symbol } & \multirow{2}{*}{ Unit } & \multicolumn{3}{|c|}{ Roof } \\
\hline & & D1 & D2 & D3 \\
\hline $\boldsymbol{R}_{T a}$ & {$\left[\mathrm{~m}^{2} \mathrm{~K} / \mathrm{W}\right]$} & 0.5483 & 0.5483 & 0.6378 \\
\hline $\boldsymbol{R}_{T b}$ & {$\left[\mathrm{~m}^{2} \mathrm{~K} / \mathrm{W}\right]$} & 2.5960 & 0.2150 & 2.6854 \\
\hline$A$ & {$\left[\mathrm{~m}^{2}\right]$} & 0.0802 & 0.0802 & 0.1016 \\
\hline$f_{a}$ & {$[-]$} & 0.05 & 0.05 & 0.05 \\
\hline$f_{b}$ & {$[-]$} & 0.9 & 0.9 & 0.9 \\
\hline $\boldsymbol{R}_{T}$, & {$\left[\mathrm{m}^{2} \mathrm{~K} / \mathrm{W}\right]$} & 1.8901 & 0.2289 & 2.0328 \\
\hline$\lambda_{A}$ & {$[\mathrm{~W} / \mathrm{mK}]$} & 0.0678 & - & 0.0678 \\
\hline$\lambda_{B}$ & {$[\mathrm{~W} / \mathrm{mK}]$} & - & - & 0.3 \\
\hline$\lambda_{C}$ & {$[\mathrm{~W} / \mathrm{mK}]$} & - & - & 0.18 \\
\hline$\lambda_{G}$ & [W/mK] & 0.04 & 0.04 & - \\
\hline$\lambda_{H}$ & {$[\mathrm{~W} / \mathrm{mK}]$} & - & 0.4391 & - \\
\hline$R_{T} ”$ & {$\left[\mathrm{~m}^{2} \mathrm{~K} / \mathrm{W}\right]$} & 1.6899 & 0.4427 & 1.7794 \\
\hline $\boldsymbol{R}_{T}$ & {$\left[\mathrm{~m}^{2} \mathrm{~K} / \mathrm{W}\right]$} & 1.79 & 0.3358 & 1.9061 \\
\hline $\boldsymbol{U}$ & {$\left[\mathrm{W} / \mathrm{m}^{2} \mathrm{~K}\right]$} & 0.5587 & 2.9777 & 0.5246 \\
\hline
\end{tabular} the tested roofs}

By using the presented relations and values of structural materials of the roof, the parameters of thermal resistances and thermal transmittance factors were determined for the roof structures under consideration. (Table 3).

Table 3. Values of parameters determined for the tested roofs.

While analysing the values of the thermal transmittance factor obtained by way of analytical calculations, it is possible to notice that none of them meets the requirements set for roofs in the applicable legal acts. In real-world solutions, roof rafters are about $18 \mathrm{~cm}$ thick (and not $10 \mathrm{~cm}$ as in built fragments) and the thickness of the applied thermal insulation in the form of mineral wool is about $30 \mathrm{~cm}$ (and not $10 \mathrm{~cm}$ as in the analysed 
case). It is also possible to use materials with better (lower) thermal conductivity coefficient $\lambda$. After a change in the thickness and quality of the materials used, it would be necessary to carry out the whole analysis again (in a manner identical to the one presented before), until obtaining the satisfactory values of parameter $U$. However, from the point of view of the performance of the photovoltaic roof tiles, a general principle that indicates the impact of the thermal transmittance factor (thermal resistance of the roof) on the reduction in the efficiency of generation of the electricity due to an increase in the temperature of the PV cells is important.

\section{Measurement of electrical parameters of photovoltaic roof tiles placed on different roof structures}

Fig. 2 presents the measuring station which serves the purpose of performing measurements in environmental conditions and electric parameters of the solar roof tiles installed in three different roofs D1 - D3 (described above). The PV cells are directed towards the south and inclined at an angle of $37^{\circ}$ in relation to the ground surface (optimal conditions for Poznan) [11-13]. Three photovoltaic roof tiles were serially connected with each other on each of the roofs, and as a result of this the total installed power on a single roof amounted to $156 \mathrm{~W}$.

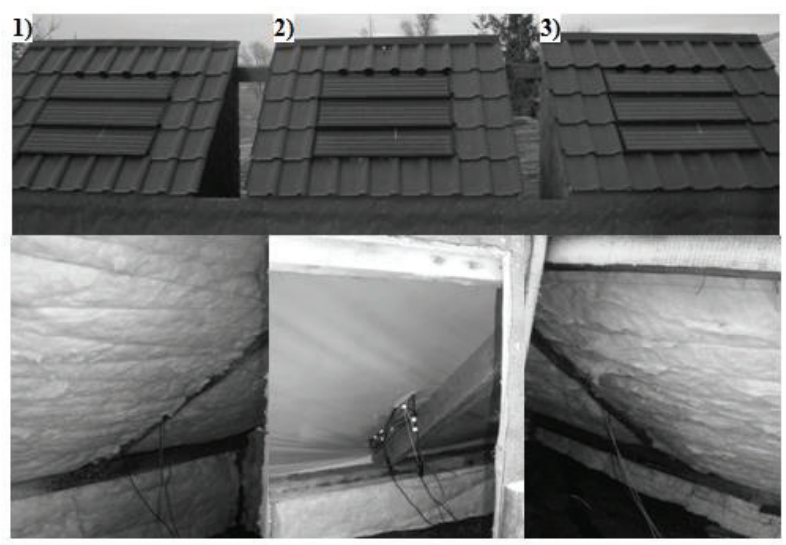

Fig. 2. View of roofs built on the basis of the presented three material structures of a different kind.

Table 4 lists the specifications of the PV roof tile in STC conditions $\left(E=1000 \mathrm{~W} / \mathrm{m}^{2}, t_{o}=25^{\circ} \mathrm{C}, A M=1,5\right)$. It occupies the area of $0.5 \mathrm{~m}^{2}$, however, in view of the required overlapping of roof tiles (laying in a way similar to the traditional roof covering) its active area containing PV cells is smaller by $0.1 \mathrm{~m}^{2}$.

The measurements of parameters of the presented solar installations were conducted on a selected sunny day in the month of August. The values of the respective measured parameters obtained during the measurements were collected in Table 5. It can be noticed that the installation built into roof D2 (which only consists of film without insulation), i.e. with the highest thermal conductivity coefficient, generated the highest power at the level of slightly less than $110 \mathrm{~W}$ (at environmental conditions - $\left.E=993.34 \mathrm{~W} / \mathrm{m}^{2}, t_{p v}=28,69^{\circ} \mathrm{C}\right)$, which is lower by about $30 \%$ than that declared by the manufacturer in the datasheet for the STC conditions.

Analysis of the measurement results demonstrates unambiguously the impact of the roof structure (used building materials) and their design thermal resistances on the values of temperatures of PV cells and air within the roof space $\left(t_{\text {gap }}\right.$ in layer $\left.D\right)$. Higher temperatures of the PV cells determine the reduction of voltages and generated power.

Table 4. Values of parameters of the PV roof tile in STC [14].

\begin{tabular}{|c|c|c|c|c|}
\hline $\begin{array}{c}\boldsymbol{U}_{\boldsymbol{m}} \\
{[\mathrm{V}]}\end{array}$ & $\begin{array}{c}\boldsymbol{I}_{\boldsymbol{m}} \\
{[\mathrm{A}]}\end{array}$ & $\begin{array}{c}\boldsymbol{P}_{\max } \\
{[\mathbf{W}]}\end{array}$ & $\begin{array}{c}\boldsymbol{v}_{\boldsymbol{I s c}} \\
{\left[\% /{ }^{\circ} \mathbf{C}\right]}\end{array}$ & $\begin{array}{c}\boldsymbol{\eta} \\
{[\%]}\end{array}$ \\
\hline 9.8 & 5.3 & 52 & 0.027 & 14.9 \\
\hline $\begin{array}{c}\boldsymbol{U}_{\boldsymbol{o c}} \\
{[\mathbf{V}]}\end{array}$ & $\begin{array}{c}\boldsymbol{I}_{\boldsymbol{s c}} \\
{[\mathrm{A}]}\end{array}$ & $\begin{array}{c}\boldsymbol{\nu}_{\boldsymbol{P}} \\
{\left[\% /{ }^{\circ} \mathbf{C}\right]}\end{array}$ & $\begin{array}{c}\boldsymbol{\nu}_{\text {Uoc }} \\
{\left[\% /{ }^{\circ} \mathbf{C}\right]}\end{array}$ & $\begin{array}{c}\boldsymbol{S} \\
{\left[\mathbf{m}^{2}\right]}\end{array}$ \\
\hline 12 & 5.55 & -0.38 & -0.285 & 0.4 \\
\hline
\end{tabular}

Taking roof D2, which has the lowest thermal resistance, as the base roof (as in the case of this structure, there is free exchange of heat from layer $D$ with the air on the building attic) the measured values were compared with the values determined analytically on the basis of temperature coefficients given by the manufacturer in the roof tile datasheet. The maximum differences in the obtained values amounted to $\pm 1.5 \%$.

Table 5. Measured values of the installation parameters with PV roof tiles placed on various structures.

\begin{tabular}{|c|c|c|c|c|}
\hline \multicolumn{2}{|c|}{$E\left[\mathbf{W} / \mathbf{m}^{2}\right]$} & 993.34 & 567.37 & 360.37 \\
\hline \multirow{8}{*}{ D1 } & $U_{o c}[\mathrm{~V}]$ & 29.98 & 30.22 & 29.93 \\
\hline & $I_{s c}[\mathbf{A}]$ & 5.33 & 2.91 & 1.62 \\
\hline & $U_{m}[\mathbf{V}]$ & 22.51 & 24.19 & 24.65 \\
\hline & $I_{m}[\mathrm{~A}]$ & 4.71 & 2.57 & 1.43 \\
\hline & $P_{\max }[\mathbf{W}]$ & 106.02 & 62.17 & 35.25 \\
\hline & $\eta[\%]$ & 8.89 & 9.13 & 8.15 \\
\hline & $t_{p v}\left[{ }^{\circ} \mathrm{C}\right]$ & 33.61 & 31.48 & 30.94 \\
\hline & $\boldsymbol{t}_{\text {gap }}\left[{ }^{\circ} \mathrm{C}\right]$ & 36.31 & 35.42 & 34.35 \\
\hline \multirow{3}{*}{ D2 } & $U_{o c}[\mathrm{~V}]$ & 30.31 & 30.53 & 30.24 \\
\hline & $I_{s c}[\mathbf{A}]$ & 5.33 & 2.76 & 1.60 \\
\hline & $U_{m}[\mathbf{V}]$ & 23.06 & 24.96 & 24.01 \\
\hline
\end{tabular}


cont. Table 5.

\begin{tabular}{|c|c|c|c|c|}
\hline \multirow{5}{*}{ D2 } & $I_{m}[\mathbf{A}]$ & 4.75 & 2.72 & 1.45 \\
\hline & $\boldsymbol{P}_{\max }[\mathrm{W}]$ & 109.54 & 67.89 & 36.26 \\
\hline & $\eta[\%]$ & 9.19 & 9.97 & 8.39 \\
\hline & $t_{p v}\left[{ }^{\circ} \mathrm{C}\right]$ & 28.69 & 27.73 & 27.21 \\
\hline & $\boldsymbol{t}_{\text {gap }}\left[{ }^{\circ} \mathrm{C}\right]$ & 29.32 & 28.91 & 28.74 \\
\hline \multirow{8}{*}{ D3 } & $U_{o c}[\mathrm{~V}]$ & 29.57 & 29.76 & 29.44 \\
\hline & $I_{s c}[\mathbf{A}]$ & 5.12 & 2.75 & 1.57 \\
\hline & $U_{m}[\mathbf{V}]$ & 22.20 & 23.87 & 24.37 \\
\hline & $I_{m}[\mathbf{A}]$ & 4.65 & 2.50 & 1.42 \\
\hline & $\boldsymbol{P}_{\max }[\mathrm{W}]$ & 103.23 & 59.68 & 34.61 \\
\hline & $\eta[\%]$ & 8.66 & 8,76 & 8.00 \\
\hline & $t_{p v}\left[{ }^{\circ} \mathrm{C}\right]$ & 34.44 & 32.84 & 31.14 \\
\hline & $t_{\text {gap }}\left[{ }^{\circ} \mathbf{C}\right]$ & 37.42 & 37.85 & 36.28 \\
\hline
\end{tabular}

The differences between the power generated by PV roof tiles, which have the highest temperature (D3) and the lowest one (D2), range between 0.5 and $12 \%$, depending on the performed measurement and the prevailing environmental conditions. On the other hand, the performance of PV roof tiles ranged between 8 and $9.97 \%$, that is, between 4 and $12 \%$, depending on the structure and the performed measurement.

\section{Conclusions}

Photovoltaic roof tiles constitute an option for persons who wish to have their own photovoltaic installation, maintaining the aesthetic appearance of their houses. However, the stricter and stricter requirements of the civil engineering industry regarding the energyefficiency of buildings and quality of building materials have an adverse effect on the performance of photovoltaic systems integrated with the building. It is necessary to conduct an accurate analysis of thermal resistances of the roof structure and to estimate the real power outputs from the installed solar installation in order to make the investor fully aware of the achieved profits and time of return on investment.

Analysis of the measuring data demonstrates unambiguously the link between the type of the roof structure and the values of idle voltages, voltages at maximum power point and generated electric power. Provision of a better roof insulation (with lower thermal transmittance factor) causes faster and stronger heating of the PV cells (resulting from worse heat exchange) and thus a decrease in efficiency and quantity of the electricity generated from photovoltaic roof tiles - from a few to several percent.

\section{References}

1. M. D’Orazio, C. Di Perna, E. Di Giuseppe, Renewable Energy 68, 378 (2014)

2. A. Gunawan, P. Hiralal, G. A. J. Amaratunga, K. Tan, S. Elmes, Photovoltaic Specialist Conf., (PVSC, 776-781, 2014)

3. G. Frydrychowicz - Jastrzębska, A. Bugała, Energies 8, 1025 (2015)

4. D. Kurz, Computational Problems of Electr. Eng., 1-5 (IEEE Xplore, Sandomierz, 2016)

5. L. Kasprzyk, Prz. Elektrotechniczny, 12, 128 (2007)

6. J. Jajczyk, Computational Problems of Electr. Eng., 1-3 (IEEE Xplore, Sandomierz, 2016)

7. K. Bednarek, R. Nawrowski, A. Tomczewski, Studies in Applied Electromagnetics and Mechanics, 22, 363-368, (IOS Press, Amsterdam, Berlin, 2002)

8. K. Bednarek, Int. J. Occup. Saf. Ergon. (JOSE), 16, 357 (2010)

9. Notice of Minister of Infrastructure and Development of 17 July 2015 on the Homogenous Text of the Regulation of the Minister of Infrastructure on the Technical Requirements to be Met by Buildings and Their Location, Journal of Laws of 2015, item 1422

10. PN-EN ISO 6946:2008 Building components and building elements - Thermal resistance and thermal transmittance

11. D. Głuchy, D. Kurz, G. Trzmiel, Prz. Elektrotechniczny 89/6, 281 (2013)

12. Haberlin H., Photovoltaics. System Designed and Practice (John Wiley \& Sons Ltd., 2012)

13. Jastrzębska G., Ogniwa słoneczne (Wydawnictwa Komunikacji i Łączności, 2013)

14. FTDS52 photovoltaic tile data sheet [www.fotton.eu], date:14.02.2017 